\title{
High signal intensity on T2 weighted cardiac magnetic resonance imaging in hypertrophic cardiomyopathy: Is it a marker of myocardial injury?
}

Shi Chen ${ }^{1}$, Luo Yong ${ }^{1}$, Liwei Huang ${ }^{2}$, Jiayu Sun ${ }^{1}$, Tianjing Zhang ${ }^{3}$, Qing Zhang ${ }^{1}$, Yucheng Chen ${ }^{1 *}$

From 18th Annual SCMR Scientific Sessions

Nice, France. 4-7 February 2015

\section{Background}

Previous studies observed the phenomenon of high signal intensity on T2 -weighted image of cardiac magnetic resonance imaging (CMR) in hypertrophic cardiomyopathy (HCM). However, the underlying histopathologic mechanism is unclear. Elevated cardiac troponin can be detected in some HCM patients. A reasonable hypothesis is that myocardial T2-high signals is a potential marker of myocaridal injury in HCM. We sought to investigate the association between cardiac troponin and the extent of T2high signals in HCM patients.

\section{Methods}

Forty-four HCM patients underwent 3.0T CMR scanning. On T2-weighted images, the number of segments with high-signal intensity(myocardium to skeletal muscle signal intensity ratio $>2$ ) and the percentage of high-signal area ( $>2 \mathrm{SD}$ above remote tissue) were measured in 16 myocardial segments along the LV mid-myocardial circumference on 3 short-axis images. The level of high sensitivity cardiac troponin $\mathrm{T}(\mathrm{hs}-\mathrm{cTnT})$ was also assessed.

\section{Results}

Myocardial T2-high signals were indentified in 33(75\%) patients and 144(20.5\%) segments.Elevated hs-cTnT was observed in $28(63.6 \%)$ patients.Cochran-Armitage test showed a statistically significant trend of increasing level of hs-cTnT with elevating number of segments with myocardial T2-high signal $(\mathrm{p}=0.002)$. Then,Pearson's test showed the percentage of myocardium with T2-high

${ }^{1}$ West China Hosptial, Chengdu, China

Full list of author information is available at the end of the article signal significantly associated with the hs-cTnT level $(\mathrm{r}=0.388, \mathrm{P}=0.009)$

\section{Conclusions}

Myocardial T2-high signals can be considered as a marker of myocardial injury in HCM patients.

\section{Authors' details}

'West China Hosptial, Chengdu, China. ${ }^{2}$ Department of Cardiovascular Ultrasound and Noninvasive Cardiology, Sichuan Academy of Medical Sciences and Sichuan People's Hospital,Chengdu, Chengdu, China. ${ }^{3}$ MR Collaborations NE Asia, Siemens Healthcare, Beijing, China.

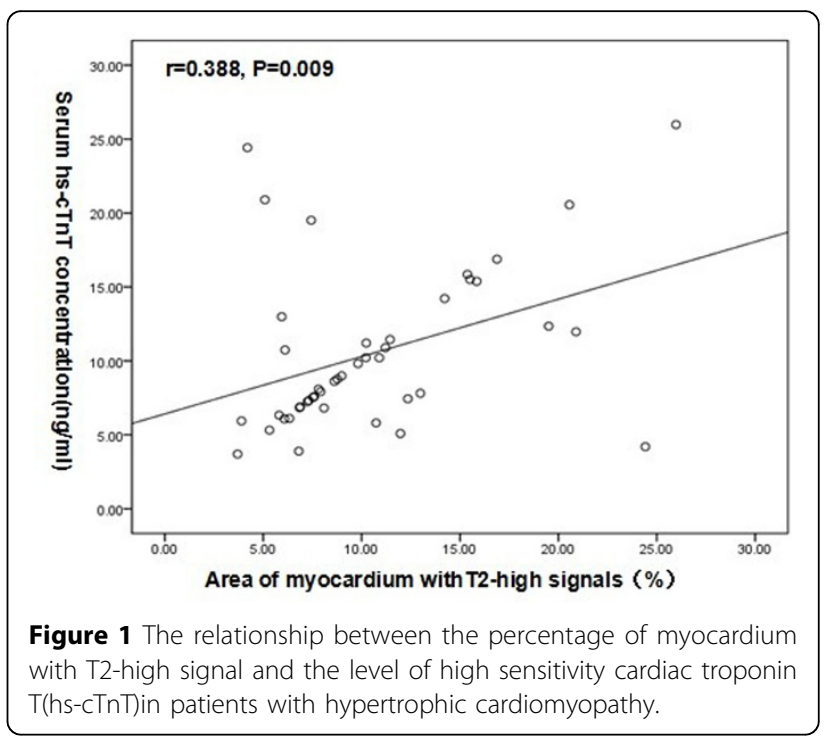


Table 1 Cardiac magnetic resonance characteristics of patients with HCM

\begin{tabular}{cc}
\hline & Study participants $(\mathrm{n}=44)$ \\
\hline LVEDV, $(\mathrm{ml})$ & $136.1 \pm 31.7$ \\
\hline LVESV, $(\mathrm{ml})$ & $49.1 \pm 15.0$ \\
\hline LVEF,(\%) & $62.7 \pm 12.0$ \\
\hline LV mass, $(\mathrm{g})$ & $155.2 \pm 54.5$ \\
\hline LV mass index,(g/m2) & $94.2 \pm 34.8$ \\
\hline Segments with T2-high signal, $\mathrm{n}(\%)$ & $144(20.5)$ \\
\hline Presence of T2-high signal, (\%) & $10.5 \pm 5.4$
\end{tabular}

LVEDV, left ventricular end diastolic volume; LVESV, left ventricular end systolic volume; LVEF, left ventricular ejection fraction;LV left ventricle

Published: 3 February 2015

doi:10.1186/1532-429X-17-S1-P289

Cite this article as: Chen et al.: High signal intensity on $\mathrm{T} 2$ weighted

cardiac magnetic resonance imaging in hypertrophic cardiomyopathy: Is it a marker of myocardial injury? Journal of Cardiovascular Magnetic Resonance

2015 17(Suppl 1):P289.

Submit your next manuscript to BioMed Central and take full advantage of:

- Convenient online submission

- Thorough peer review

- No space constraints or color figure charges

- Immediate publication on acceptance

- Inclusion in PubMed, CAS, Scopus and Google Scholar

- Research which is freely available for redistribution

Submit your manuscript at www.biomedcentral.com/submit 